\title{
The Influence of Hydrazine Reduction on Metal Dispersion and Support Morphology in Bimetallic Ru-Au/MgO Catalysts
}

\author{
A. G. Shastri and J. Schwank \\ Department of Chemical Engineering, University of Michigan, Ann Arbor, Michigan 48109
}

Received July 9, 1985

\begin{abstract}
The influence of hydrazine reduction on metal dispersion, particle size distribution, and support morphology was investigated for a series of bimetallic $\mathrm{Ru}-\mathrm{Au} / \mathrm{MgO}$ catalysts. The catalysts were prepared by impregnation of $\mathrm{MgO}$ with chlorine-containing precursor salt solutions. Hydrazine reduction significantly lowered the residual chlorine content of the catalysts and allowed the formation of high-surface-area $\mathrm{MgO}$. This, in turn, led to much higher Ru metal dispersions as compared to that obtained after $\mathrm{H}_{2}$ reduction alone. X-Ray energy dispersive spectroscopy (EDS) proved that bimetallic Ru-Au aggregates were confined to a particle size range of less than $5 \mathrm{~nm}$. Particles larger than $10 \mathrm{~nm}$ contained without exception monometallic Au. The hydrazine-treated catalysts did not show the suppression in catalytic activity for $\mathrm{CO}$ hydrogenation that was observed in $\mathrm{H}_{2}$-reduced $\mathrm{Ru} / \mathrm{MgO}$ catalysts. The increased metal dispersion and restored catalytic activity of Ru in the hydrazine-treated catalysts may be linked to the absence of chlorine contamination of the support. 일 1986 Academic Press, Inc.
\end{abstract}

\section{INTRODUCTION}

In bimetallic catalysts, the nature of the support and the details of catalyst preparation and pretreatment can play a major role in controlling particle size and morphology, the extent of bimetallic cluster formation, and ultimately the catalytic behavior. $\mathrm{Ru}-$ Au catalysts represent an important model system for the investigation of bimetallic cluster formation between metal components which are immiscible in the bulk state. Previous work on the Ru-Au system clearly demonstrated that $\mathrm{MgO}$-supported catalysts were structurally quite different compared to $\mathrm{SiO}_{2}$-supported ones (1-9). In contrast to the acidic and refractory nature of $\mathrm{SiO}_{2}$ supports, $\mathrm{MgO}$ is basic and can undergo massive structural changes depending on preparation and reaction conditions. Typical catalyst preparation via impregnation of simple cubic $\mathrm{MgO}$ with aqueous catalyst precursor solutions can lead to a transformation into hexagonal $\mathrm{Mg}(\mathrm{OH})_{2}$. The subsequent dehydration of $\mathrm{Mg}(\mathrm{OH})_{2}$ to $\mathrm{MgO}$ during catalyst pretreatment is ac- companied by about $55 \%$ reduction in molar volume, nonuniform release of water, and a cooperative movement of $\mathrm{Mg}^{2+}$ and $\mathrm{O}^{2-}$ ions $(10-20)$. Consequently, the $\mathrm{MgO}$ surface created by such a dehydration process tends to be highly nonuniform and rich in defects $(21)$. It is conceivable that these defect-rich $\mathrm{MgO}$ structures are quite susceptible to metal-support interactions. In the case of $\mathrm{Au} / \mathrm{MgO}$, the reaction between the basic oxide material and the precursor species $\mathrm{AuCl}_{4}^{-}$generally results in high $\mathrm{Au}$ dispersions. The presence of such highly dispersed Au was found to cause structural destabilization of $\mathrm{MgO}$ resulting in increased rates of isotopic oxygen exchange between gas-phase and $\mathrm{MgO}$ oxygen (22, 23). The precursor species $\mathrm{Ru}^{3+}$, on the other hand, tends to precipitate as hydroxide, thereby causing poor Ru dispersion on $\mathrm{MgO}$. Moreover, $\mathrm{MgO}$ seems to exert a "negative support effect' on Ru, suppressing its catalytic activity in the hydrogenolysis of ethane and in the CO hydrogenation (1). Similar activity losses were also reported for $\mathrm{Pt} / \mathrm{MgO}$ after reduction in $\mathrm{H}_{2}$ at 
$773 \mathrm{~K}$ and were ascribed by the authors to the formation of a platinum-magnesia complex in which electron transfer occurs from Pt to $\mathrm{MgO}$ (24).

In the case of $\mathrm{Ru} / \mathrm{MgO}$, substituting hydrazine $\left(\mathrm{N}_{2} \mathrm{H}_{4}\right)$ as the reducing agent in place of $\mathrm{H}_{2}$ during catalyst preparation eliminated the suppression in activity and restored the normal catalytic behavior of $\mathrm{Ru}$ in $\mathrm{CO}$ hydrogenation (25). These observations prompted us to investigate in more detail the influence of hydrazine reduction on metal dispersions and on bimetallic $\mathrm{Ru}-$ $\mathrm{Au}$ particle formation in $\mathrm{MgO}$-supported catalysts. Similar to the previously reported results on $\mathrm{H}_{2}$-reduced $\mathrm{Ru}-\mathrm{Au} / \mathrm{MgO}$ catalysts $(1,3,9,25)$, a multifaceted characterization approach has been used to map out the size distribution and composition of metal particles in the hydrazine-reduced catalysts. Special emphasis is placed on the initial stages of metal particle formation and stability of metal dispersions as a function of temperature and reducing environment. Furthermore, the influence of $\mathrm{Au}$ on spillover of atomic hydrogen from $\mathrm{Ru}$ sites will be discussed.

\section{EXPERIMENTAL}

The catalysts were prepared by impregnating $\mathrm{MgO}$ (Carlo Erba, reagent grade) with a solution of $\mathrm{RuCl}_{3} \cdot \mathrm{H}_{2} \mathrm{O}$ (Rudi-Pont reagent grade) and $\mathrm{HAuCl}_{4} \cdot 3 \mathrm{H}_{2} \mathrm{O}$ (Carlo Erba RPE). After drying for $4 \mathrm{hr}$ at $388 \mathrm{~K}$, the samples were treated under stirring in an $\approx 0.5 \mathrm{M} \mathrm{NaOH}$ solution of hydrazine, followed by $4 \mathrm{hr}$ evacuation at $388 \mathrm{~K}$. Each catalyst was assigned a code, containing the letter $\mathrm{R}$ for $\mathrm{Ru}, \mathrm{M}$ for $\mathrm{MgO}, \mathrm{H}$ for hydrazine reduction, and a three-digit number representing the atomic percentage of $\mathrm{Ru}$ on the basis of the total number of Ru and Au atoms in the catalyst. The hydrazinereduced catalysts were stored in air and are referred to as " $\mathrm{N}_{2} \mathrm{H}_{4}$-only"-treated samples. Aliquots of these hydrazine-reduced samples were subsequently subjected to a second reduction step in $\mathrm{H}_{2}$ at $673 \mathrm{~K}$. These samples are labeled as " $\mathrm{N}_{2} \mathrm{H}_{4}+673 \mathrm{~K} \mathrm{H}_{2}$ " treated. The bulk composition of the samples was determined by neutron activation analysis (Table 1).

The surface area of the catalysts was determined by the single-point BET technique. $\mathrm{N}_{2}$ at $77.3 \mathrm{~K}$ was used as adsorbate in a Quantachrome Monosorb surface area analyzer. The surface areas obtained via the single-point technique were generally accurate within $\pm 5 \%$ error. Crystal structures of both the metals and the support were determined by $\mathrm{X}$-ray diffraction in a Philips X-ray powder diffractometer. Average support and metal crystallite sizes were obtained from X-ray line broadening using Scherrer's equation after correcting for the instrumental contribution.

Metal particle size distributions were obtained by high-resolution transmission electron microscopy carried out in a JEOL100CX microscope equipped with a side-entry goniometer stage. The catalyst powder was placed on holey carbon films mounted on standard copper or beryllium grids. Specimen areas protruding into the holes of the holey-carbon film were selected for microscopic examination to avoid the obscuring effect of the supporting carbon film. The microscope was equipped with an ASID-4D scanning attachment and a lithium-drifted solid-state X-ray detector for elemental analysis. Data aquisition was carried out with a multichannel analyzer connected to a ND 6620 computer. For elemental analysis of individual metal particles having a diameter of more than $4 \mathrm{~nm}$, a suitable sampling area was identified and photographed in the transmission mode, and then the machine was switched over to the scanning transmission mode for elemental analysis by energy-dispersive $\mathrm{X}$-ray spectroscopy. A 10-nm electron probe was focused on individual metal particles of interest and X-ray counts were acquired for 200 sec. In the JEOL microscope used, metal particles smaller than $3 \mathrm{~nm}$ do not provide sufficient $X$-ray counting statistics to derive meaningful information on individual particles. Nevertheless, some information could 
TABLE 1

Bulk Analysis and BET Surface Area

\begin{tabular}{|c|c|c|c|c|c|}
\hline \multirow[t]{3}{*}{ Sample code } & \multicolumn{2}{|c|}{$\begin{array}{l}\text { Metal loading } \\
\quad(w t \%)\end{array}$} & \multirow{3}{*}{$\begin{array}{l}\text { Chlorine } \\
\text { (wt\%) }\end{array}$} & \multicolumn{2}{|c|}{ BET surface area $\left(\mathrm{m}^{2} / \mathrm{g}\right)$} \\
\hline & & & & \multirow{2}{*}{ " $\mathrm{N}_{2} \mathrm{H}_{4}$-only" } & \multirow[t]{2}{*}{$" \mathrm{~N}_{2} \mathrm{H}_{4}+673 \mathrm{~K} \mathrm{H}_{2} "$} \\
\hline & $\mathrm{Ru}$ & $\mathrm{Au}$ & & & \\
\hline RMH100 & 4.6 & - & 0.088 & 25.8 & 152.1 \\
\hline RMH093 & 3.28 & 0.468 & 0.068 & 30.4 & 125.9 \\
\hline RMH014 & 0.26 & 3.109 & 0.162 & 27.3 & 112.4 \\
\hline
\end{tabular}

be obtained by rastering the beam over a suitable region containing many small particles.

For metal dispersion measurements via gas chemisorption, a standard catalyst pretreatment routine was adopted consisting of the following steps: loading of about $0.1-$ $0.3 \mathrm{~g}$ of catalyst into a static volumetric high-vacuum system and evacuation at room temperature; heating under dynamic vacuum to $673 \mathrm{~K}$ and further evacuation at this temperature for $4 \mathrm{hr}$; exposure to a first dose of research grade $\mathrm{H}_{2}(33.3 \mathrm{kPa})$ at 673 $\mathrm{K}$ for $16 \mathrm{hr} ; 1 \mathrm{hr}$ evacuation at $673 \mathrm{~K}$; exposure to a second dose of research grade $\mathrm{H}_{2}$ at the same temperature and pressure for 4 $\mathrm{hr}$; evacuation at $673 \mathrm{~K}$ for $2 \mathrm{hr}$. Then, the samples were cooled to the desired chemisorption temperature under dynamic vacuum.

The dispersion of $\mathrm{Ru}$ and Au was measured using a recently developed stepwise chemisorption and titration procedure $(8$, 9). The technique is based upon differences in the chemisorption characteristics of the two metal components. $\mathrm{H}_{2}$ is adsorbed only on Ru but not on Au allowing us to obtain the dispersion of $\mathrm{Ru} . \mathrm{O}_{2}$ adsorption at room temperature serves as a second independent measure of the $\mathrm{Ru}$ dispersion, since there is no $\mathrm{O}_{2}$ adsorption on $\mathrm{Au}$ at room temperature. At $473 \mathrm{~K}$, however, both Ru and $\mathrm{Au}$ chemisorb oxygen. Weakly adsorbed oxygen is removed by evacuation and then the strongly held oxygen is titrated with $\mathrm{H}_{2}$ at $373 \mathrm{~K}$. In our previous work we found that only oxygen adsorbed on Ru sites could be titrated with $\mathrm{H}_{2}$ at $373 \mathrm{~K}$ while the oxygen adsorbed on Au sites did not react with $\mathrm{H}_{2}$ to any significant extent at this temperature. Oxygen chemisorption at $473 \mathrm{~K}$ and $\mathrm{H}_{2} / \mathrm{O}_{2}$ titration at $373 \mathrm{~K}$ are used for obtaining the Au dispersion. A more detailed description of the technique and a critical discussion of adsorption stoichiometries and possible complications arising in this stepwise chemisorption and titration procedure have been published previously $(8,9)$.

\section{RESULTS AND DISCUSSION}

\section{Support Structure and Surface Area}

The BET surface areas are listed in Table 1. The " $\mathrm{N}_{2} \mathrm{H}_{4}$-only"-treated samples had relatively low BET surface areas. X-Ray diffraction showed that the $\mathrm{MgO}$ had undergone complete bulk hydration into $\mathrm{Mg}(\mathrm{OH})_{2}$ during catalyst impregnation.

When the hydrazine reduction was followed by an additional reduction step in $\mathrm{H}_{2}$ at $673 \mathrm{~K}$, the BET surface area increased by a factor of 4 to 6 , and drastic changes were observed both in the morphology of the support and in the metal particle size distribution. X-Ray diffraction gave $\mathrm{MgO}$ patterns with significant line broadening indicating small $\mathrm{MgO}$ crystallite sizes. A similar decrease in $\mathrm{MgO}$ particle size and increase in BET surface area upon dehydration of $\mathrm{Mg}(\mathrm{OH})_{2}$ have been observed in our previous work $(20,21)$. The presence of substantial amounts $(>1 \mathrm{wt} \%)$ of residual chlorine left behind on the $\mathrm{MgO}$ 
during catalyst preparation prevents this surface area increase during the dehydration of $\mathrm{Mg}(\mathrm{OH})_{2}$; on $\mathrm{Ru}-\mathrm{Au} / \mathrm{MgO}$ catalysts which were reduced at $673 \mathrm{~K}$ in $\mathrm{H}_{2}$ alone, a significant amount of chlorine contamination (1.3-2.2 wt\%) was found, and consequently the BET surface areas remained low in the range of approximately 30-40 $\mathrm{m}^{2} / \mathrm{g}(20)$.

The drastic increase of the BET surface areas during dehydration of the support in the hydrazine-reduced samples indicates low residual chlorine contamination, as confirmed by the results of neutron activation analysis (Table 1). The catalyst preparation for all the $\mathrm{MgO}$-supported catalysts reported here and in Ref. (20) was identical and involved the same chlorine-containing precursor salt solutions. The only difference is the $\mathrm{H}_{2}$-versus- $\mathrm{N}_{2} \mathrm{H}_{4}$ reduction. It appears that the hydrazine treatment step is very effective in preventing the buildup of chlorine contamination on the $\mathrm{MgO}$ support. Similar beneficial effects of hydrazine reduction have been found for other bimetallic systems. Hydrazine reduction was vastly superior to borohydride reduction in the preparation of unsupported $\mathrm{Pd}-\mathrm{Au}$ alloys, resulting in much lower $\mathrm{Na}$ impurity levels (30).

Wide-angle X-ray scattering (WAXS) failed to detect any $\mathrm{Ru}$ peaks in the samples treated with " $\mathrm{N}_{2} \mathrm{H}_{4}$-only" and with " $\mathrm{N}_{2} \mathrm{H}_{4}$ $+673 \mathrm{~K} \mathrm{H}_{2}$ " indicating $\mathrm{Ru}$ particle sizes less than $4 \mathrm{~nm}$. In the " $\mathrm{N}_{2} \mathrm{H}_{4}$-only"-treated samples no Au peaks were detected. However, in the " $\mathrm{N}_{2} \mathrm{H}_{4}+673 \mathrm{~K} \mathrm{H}_{2}$ "-treated samples of catalysts RMH093 and RMH014, Au peaks were found corresponding to volume average $\mathrm{Au}$ particle sizes of 23.4 and $20.2 \mathrm{~nm}$, respectively.

\section{Metal Dispersions}

To obtain information about the dispersion of the individual metal components in the bimetallic catalysts, the stepwise chemisorption and $\mathrm{H}_{2} / \mathrm{O}_{2}$ titration procedure mentioned before was employed. Figure 1 shows typical adsorption isotherms ob- tained for catalyst RMH093. For determining the amount of strongly adsorbed hydrogen two complete isotherms were measured. The first isotherm provided information about the total gas uptake. After evacuation at the adsorption temperature (room temperature for $\mathrm{H}_{2}$ adsorption and $373 \mathrm{~K}$ for $\mathrm{H}_{2} / \mathrm{O}_{2}$ titrations) a second adsorption isotherm was taken to measure the amount of weakly adsorbed hydrogen. The difference between the first and second isotherm provided the amount of strongly adsorbed hydrogen which was used for the calculation of metal dispersions. This approach takes into account the possible spillover of atomic hydrogen to $\mathrm{Au}$ or support sites. To arrive at meaningful Au dispersions, the total oxygen uptake at $473 \mathrm{~K}$ was first measured and corrected for the weakly held amount of oxygen that could be removed by evacuation at $473 \mathrm{~K}$. Lowering the temperature to $373 \mathrm{~K}$ generally resulted in desorption of some $\mathrm{O}_{2}$ in addition to the weakly adsorbed amount of oxygen at 473 $\mathrm{K}(8,9)$. This additional loss of $\mathrm{O}_{2}$ was also taken into account for calculating the amount of strongly held oxygen which could not be removed by evacuation within the temperature range of $373-473 \mathrm{~K}$. Finally, the $\mathrm{Au}$ dispersion was determined based on the difference between the corrected amount of strongly held oxygen at $473 \mathrm{~K}$ and the oxygen which could be titrated with $\mathrm{H}_{2}$ at $373 \mathrm{~K}$.

This approach is justified in view of our previous observation that oxygen chemisorbed on monometallic $\mathrm{Au} / \mathrm{SiO}_{2}$ and $\mathrm{Au} /$ $\mathrm{MgO}$ cannot be removed by evacuation at $473 \mathrm{~K}(8,9)$. Recent experiments on $\mathrm{Au}$ single crystals following our proposed chemisorption procedure at $473 \mathrm{~K}$ failed to detect any dissociative chemisorption of molecular oxygen $(26,27)$. However, it is well known that atomic oxygen will chemisorb on Au surfaces and desorb at temperatures around $600-680 \mathrm{~K}$ as $\mathrm{O}_{2}$ gas $(27,28)$. Our supported gold catalysts show strong chemisorption of oxygen at $473 \mathrm{~K}$. The adsorbed oxygen can easily be removed by 

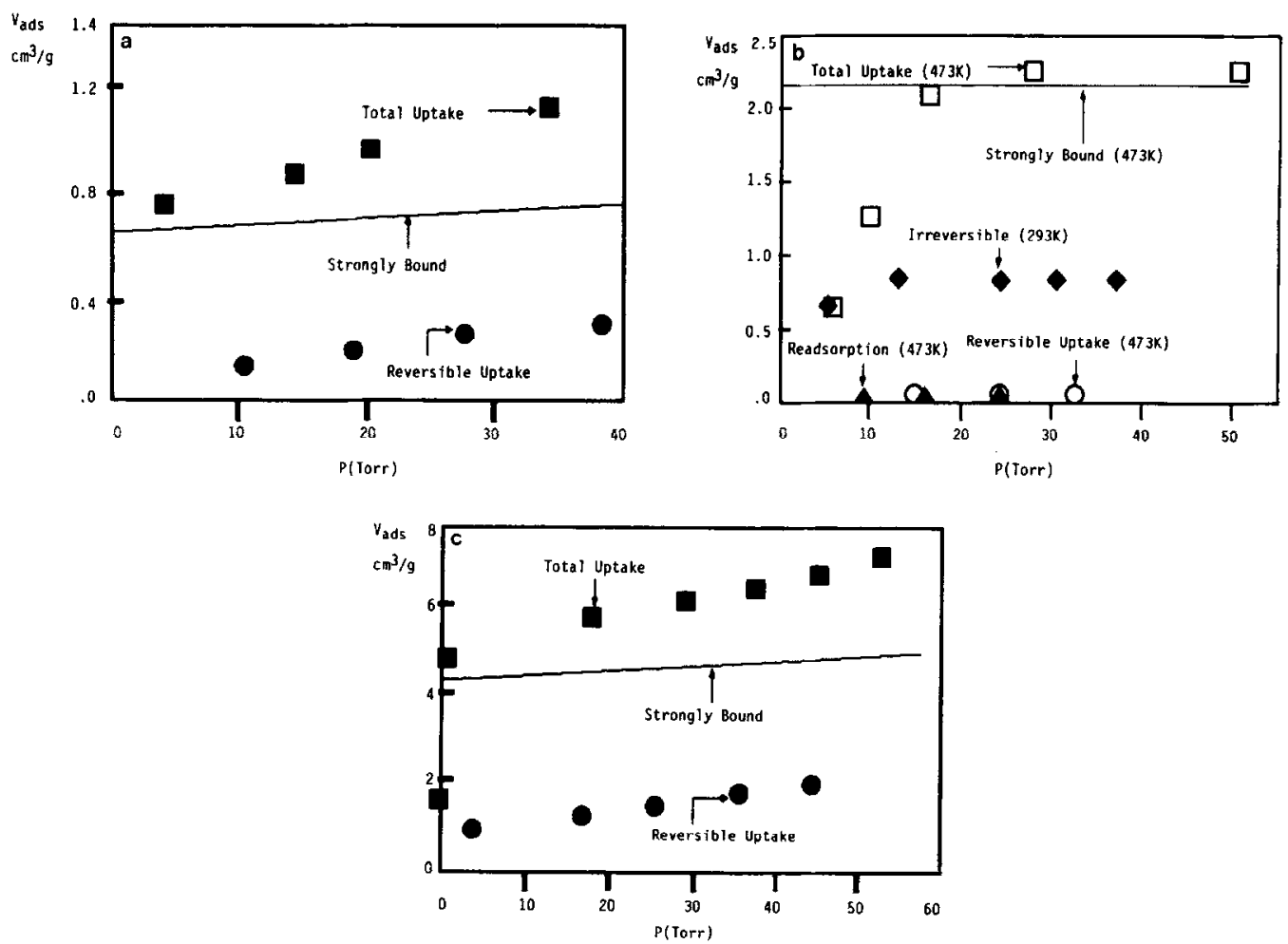

FIG. 1. Typical set of adsorption isotherms obtained for catalyst $\mathrm{RMH093,} \mathrm{"} \mathrm{N}_{2} \mathrm{H}_{4}+673 \mathrm{~K} \mathrm{H}_{2}$ " treated. (a) $\mathrm{H}_{2}$ chemisorption at $293 \mathrm{~K}$. (b) $\mathrm{O}_{2}$ chemisorption at 293 and $473 \mathrm{~K}$. (c) $\mathrm{H}_{2}$ consumed in the titration of chemisorbed $\mathrm{O}_{2}$ at $373 \mathrm{~K}$.

evacuation at $623 \mathrm{~K}$, a behavior which is typical for desorption of atomic oxygen from $\mathrm{Au}$. This indicates that there must be some source of atomic oxygen present in our supported catalysts. One possible source could be the oxide support itself. In previous work we discovered that impregnation of oxides with highly dispersed $\mathrm{Au}$ can dramatically increase the isotopic oxygen exchange activity of $\mathrm{MgO}$ and $\mathrm{SiO}_{2}$ $(22,23)$. The isotopic oxygen exchange process is likely to involve some breakage of molecular oxygen bonds either on the oxide surface or on the gold/oxide interface. Some atomic oxygen could also be generated on trace impurity sites. Our neutron activation results, however, indicate that if there are any metal impurities in our catalysts they must be of the order of parts per million levels. Of course, in the case of bimetallic $\mathrm{Ru}-\mathrm{Au}$ catalysts, $\mathrm{Ru}$ might be the source of atomic oxygen for chemisorption on $\mathrm{Au}$ sites via spillover.

The oxygen species adsorbed on Au do not react to any measurable extent with molecular $\mathrm{H}_{2}$ at $373 \mathrm{~K}$, a temperature at which the reactivity of $\mathrm{H}_{2}$ with oxygen adsorbed on $\mathrm{Ru}$ is very high. This offers the opportunity to employ $\mathrm{H}_{2} / \mathrm{O}_{2}$ titration at 373 $\mathrm{K}$ to discern between $\mathrm{Ru}$ and $\mathrm{Au}$ surface sites. It is very crucial to keep the titration temperature at $373 \mathrm{~K}$, since on monometallic $\mathrm{Au}$ catalysts the reaction between $\mathrm{H}_{2}$ and adsorbed oxygen reaches a measurable rate at temperatures exceeding $423 \mathrm{~K}$ (see Table 2).

The results of the stepwise chemisorption and titration procedure are summarized in Table 3. From the gas uptake values, the number of both $\mathrm{Ru}$ as well as $\mathrm{Au}$ surface atoms can be determined, based on adsorption stoichiometries of $\mathrm{Ru} / \mathrm{H}=1$, 
TABLE 2

$\mathrm{H}_{2} / \mathrm{O}_{2}$ Titration on $3.46 \mathrm{wt} \% \mathrm{Au} / \mathrm{MgO}$ as a Function of Temperature after Preadsorption of $3.46 \mu \mathrm{mol}$ of $\mathrm{O}_{2} / \mathrm{g}$ of Catalyst at $473 \mathrm{~K}$

\begin{tabular}{ccc}
\hline $\begin{array}{c}\mathrm{H}_{2} / \mathrm{O}_{2} \text { titration temperature } \\
(\mathrm{K})\end{array}$ & $\begin{array}{c}\mathrm{H}_{2} \text { uptake } \\
(\mu \mathrm{mol} / \mathrm{g} \text { catalyst })\end{array}$ & $\begin{array}{c}\text { mole of } \mathrm{H}_{2} \text { consumed } \\
\text { mole of adsorbed } \mathrm{O}_{2}\end{array}$ \\
\hline 373 & - & - \\
423 & 1.25 & 0.36 \\
473 & 1.87 & 0.54 \\
\hline
\end{tabular}

$\mathrm{Ru} / \mathrm{O}_{2}=1$, and $\mathrm{Au} / \mathrm{O}_{2}=4$. If $\mathrm{Ru}$ and $\mathrm{Au}$ was present in monometallic particles only without formation of any bimetallic particles, one could translate the metal dispersion directly into surface average particle sizes $d(\mathrm{Ru})$ and $d(\mathrm{Au})$. These estimated particle sizes are also listed in Table 3. One interesting observation made in this context is that the relative amount of weakly adsorbed hydrogen that can be removed by evacuation at $373 \mathrm{~K}$ decreases as the gold content increases. This phenomenon is not restricted to the hydrazine-reduced $\mathrm{Ru}-$ $\mathrm{Au} / \mathrm{MgO}$ catalysts discussed in this paper, but is also seen in the results reported previously on $\mathrm{H}_{2}$-reduced $\mathrm{Ru}-\mathrm{Au} / \mathrm{MgO}$ and $\mathrm{Ru}-\mathrm{Au} / \mathrm{SiO}_{2}$ catalysts $(8,9)$. One explanation could be that weakly adsorbed atomic hydrogen is highly mobile and can migrate around on the surface of metal particles and on the support. Because of the low $\mathrm{Au}-\mathrm{H}$ bond strength, atomic hydrogen species arriving at gold sites tend to recombine to molecular $\mathrm{H}_{2}$ and desorb into the gas phase. However, atomic hydrogen spilled over onto the support has a higher residence time than on $\mathrm{Au}$ sites and requires evacuation for removal. This interpretation is in agreement with the observation that on bimetallic $\mathrm{Ru}-\mathrm{Au}$ no increased hydrogen uptake takes place as compared to monometallic Ru with similar Ru metal loadings ( 8 , 9 ). Thus our technique of subtracting the weakly adsorbed gases corrects for spillover of atomic hydrogen if it should be taking place under our experimental conditions.

\section{Particle Morphology and Composition}

In order to compare the influence of " $\mathrm{N}_{2} \mathrm{H}_{4}$-only"-vs- " $\mathrm{N}_{2} \mathrm{H}_{4}+673 \mathrm{~K} \mathrm{H}_{2}$ " reduction on support morphology and metal particle size distribution, transmission electron microscopy (TEM) and energy dispersive X-ray spectroscopy (EDS) were carried out. The massive changes in support morphology and the significantly increased metal particle sizes after " $\mathrm{N}_{2} \mathrm{H}_{4}+673 \mathrm{~K}$ $\mathrm{H}_{2}$ " reduction can readily be seen in the representative micrographs for each sample (Fig. 2). The corresponding changes in metal particle size distributions are shown in the histograms of the $\mathrm{N}_{2} \mathrm{H}_{4}$-reduced and $\left(\mathrm{N}_{2} \mathrm{H}_{4}+\mathrm{H}_{2}\right)$-reduced catalysts (Fig. 3). The main feature of the histograms is that the number of very small particles $(<1 \mathrm{~nm})$ is not significantly affected by the $\mathrm{H}_{2}$ reduction at $673 \mathrm{~K}$, while the particles with an initial size of more than $1 \mathrm{~nm}$ agglomerate readily into larger particles, thus shifting the size distribution toward higher values.

TABLE 3

Summary of Stepwise Chemisorption and $\mathrm{H}_{2} / \mathrm{O}_{2}$ Titration Results on " $\mathrm{N}_{2} \mathrm{H}_{4}+673 \mathrm{~K} \mathrm{H}_{2}$ "-Treated Catalysts

\begin{tabular}{|c|c|c|c|c|c|c|c|c|c|c|}
\hline \multirow{2}{*}{$\begin{array}{c}\text { Sample } \\
\text { code }\end{array}$} & \multicolumn{3}{|c|}{$\mathrm{H}_{2}(293 \mathrm{~K})$} & \multicolumn{3}{|c|}{$\mathrm{O}_{2}(293 \mathrm{~K})$} & \multirow{2}{*}{$\frac{\mathrm{O}_{2}(473 \mathrm{~K})}{\begin{array}{c}\mathrm{O}_{2} \text { uptake } \\
\left(\mathrm{cm}^{3} / \mathrm{g}\right)\end{array}}$} & \multicolumn{3}{|c|}{$\mathrm{H}_{2} / \mathrm{O}_{2}(373 \mathrm{~K})$} \\
\hline & $\begin{array}{c}\mathrm{H}_{2} \text { uptake } \\
\left(\mathrm{cm}^{3} / \mathrm{g}\right)\end{array}$ & $\mathbf{H} / \mathbf{R u}$ & $\begin{array}{c}d(\mathrm{Ru}) \\
(\mathrm{nm})\end{array}$ & $\begin{array}{c}\mathrm{O}_{2} \text { uptake } \\
\left(\mathrm{cm}^{3} / \mathrm{g}\right)\end{array}$ & $\mathrm{O}_{2} / \mathrm{Ru}$ & $\begin{array}{c}d(\mathrm{Ru}) \\
(\mathrm{nm})\end{array}$ & & $\begin{array}{c}\mathrm{H}_{2} \text { uptake } \\
\left(\mathrm{cm}^{3} / \mathrm{g}\right)\end{array}$ & $\mathrm{Au}_{\mathrm{s}} / \mathrm{Au}$ & $\begin{array}{c}d(\mathrm{Au}) \\
(\mathrm{nm})\end{array}$ \\
\hline RMH 100 & 1.70 & 0.333 & 2.8 & - & - & & - & - & - & - \\
\hline RMH093 & 0.65 & 0.179 & 5.1 & 0.83 & 0.114 & 8.0 & 2.131 & 4.375 & 0.163 & 6.7 \\
\hline RMH014 & 0.013 & 0.045 & 20.3 & 0.024 & 0.041 & 22.2 & 0.179 & 0.305 & 0.0314 & 34.6 \\
\hline
\end{tabular}


TABLE 4

Average Metal Particle Sizes $d_{n}, d_{s}, d_{v}$, and Summary of EDS Analysis

\begin{tabular}{|c|c|c|c|c|c|c|c|c|c|c|}
\hline \multirow[t]{3}{*}{ Sample code } & \multicolumn{3}{|c|}{ " $\mathrm{N}_{2} \mathrm{H}_{4}$-only" } & \multicolumn{3}{|c|}{$" \mathrm{~N}_{2} \mathrm{H}_{4}+673 \mathrm{~K} \mathrm{H}_{2}$ " } & \multicolumn{4}{|c|}{$\begin{array}{l}\% \text { Metal particles in each } \\
\text { composition category }\end{array}$} \\
\hline & \multirow{2}{*}{$d_{\mathrm{n}}$} & \multirow[t]{2}{*}{$d_{\mathrm{s}}$} & \multirow[t]{2}{*}{$d v$} & \multirow[t]{2}{*}{$d_{n}$} & \multirow[t]{2}{*}{$d_{\mathrm{s}}$} & \multirow[t]{2}{*}{$d_{v}$} & & & & \\
\hline & & & & & & & $\begin{array}{c}\text { Ru } \\
\text { only }\end{array}$ & $\begin{array}{c}\mathrm{Ru}+ \\
\text { trace Au }\end{array}$ & $\begin{array}{c}\mathrm{Au}+ \\
\text { trace } \mathrm{Ru}\end{array}$ & $\begin{array}{l}\text { Au } \\
\text { only }\end{array}$ \\
\hline RMH100 & 1.8 & 2.0 & 2.3 & 2.3 & 2.9 & 3.5 & 100 & - & 一 & - \\
\hline RMH093 & 2.0 & 2.3 & 2.6 & 3.7 & 5.2 & 6.5 & 73 & 20 & 0 & 7 \\
\hline RMH014 & 9.2 & 12.8 & 15.1 & 8.9 & 13.1 & 19.9 & 0 & 13 & 14 & 73 \\
\hline
\end{tabular}

Preliminary electron $\mu-\mu$ diffraction studies indicate that the alignment of metal particles with respect to the oxide substrate changes as a function of metal particle size. We suspect that these differences in particle alignment might influence the agglomeration characteristics.

Table 4 summarizes the number average particle sizes obtained from electron microscopy $\left(d_{n}=\Sigma n_{i} d_{i} / \Sigma n_{i}\right)$ along with the computed values of surface average particle sizes $\left(d_{s}=\Sigma n_{i} d_{i}^{3} / \Sigma n_{i} d_{i}^{2}\right)$ and volume average particle sizes $\left(d_{v}=\Sigma n_{i} d_{i}^{4} / \Sigma n_{i} d_{i}^{3}\right)$ to allow a direct comparison with chemisorption and WAXS results. $n_{i}$ represents the number of particles of size $d_{i}$. The good agreement in the Ru particle size results obtained by chemisorption (Table 3) and by electron microscopy (Table 4) indicates that there is no significant problem associated with hydrogen spillover, in contrast to recent observations on the $\mathrm{Ru}-\mathrm{Cu}$ system (29).

To obtain information concerning the composition of individual metal particles, EDS was carried out using the scanning transmission mode. In view of the small signal-to-noise ratio and the low X-ray count obtained on such small metal particles, only a qualitative analysis can be attempted. Following a previously proposed strategy (25), we grouped the EDS spectra into four categories, namely, spectra showing signals of Ru only, Ru with a trace of Au, Au with a trace of Ru, and Au only. Figure 4 shows examples of typical EDS spectra obtained on individual particles. Table 4 summarizes the EDS results obtained on the " $\mathrm{N}_{2} \mathrm{H}_{4}+$ $673 \mathrm{~K} \mathrm{H}_{2}$ "'-treated catalysts RMH093 and RMH014. For each catalyst, 50 metal particles $2-11 \mathrm{~nm}$ in diameter were analyzed. Table 4 shows the percentage of these metal particles belonging to one of the four above-mentioned composition categories. There was no significant difference in the EDS spectra of the " $\mathrm{N}_{2} \mathrm{H}_{4}$-only"- and the “ $\mathrm{N}_{2} \mathrm{H}_{4}+673 \mathrm{~K} \mathrm{H} \mathrm{H}_{2}$ "-reduced catalysts. The monometallic gold particles listed in Table 4 as "Au only" were without exception larger than $9 \mathrm{~nm}$.

\section{Catalyst Microstructure}

Interesting details concerning the microstructure of the catalysts are provided utilizing the rich data base accumulated through the various characterization techniques. We will now discuss each of the three samples in turn. First, the monometallic Ru sample RMH100 has a very high metal dispersion corroborated by TEM, chemisorption, and WAXS results which are in excellent agreement. The Ru-rich sample RMH093 shows good agreement between microscopy, chemisorption, and WAXS as far as Ru is concerned. However, there is an important discrepancy between the average Au particle size as derived from chemisorption and WAXS. The WAXS particle size is by more than a factor of 3 larger than the chemisorption particle size. In contrast to chemisorption, WAXS requires a certain degree of long-range order and coherence length, and is not sensitive to metal in a state of very high disper- 

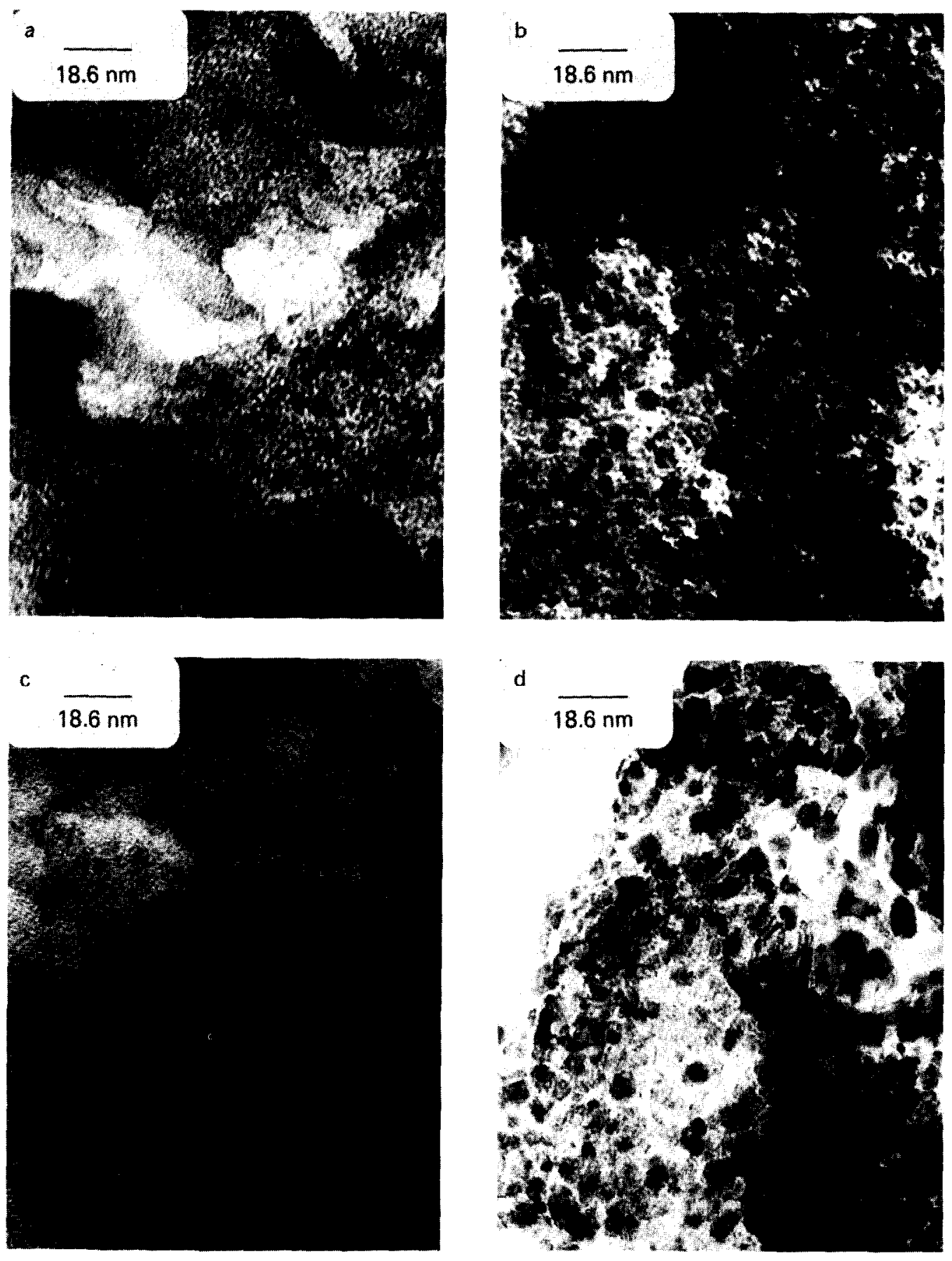

FIG. 2. Representative transmission electron micrographs of catalysts. (a) Sample RMH100, " $\mathrm{N}_{2} \mathrm{H}_{4}$ only" treated. (b) Sample RMH100, " $\mathrm{N}_{2} \mathrm{H}_{4}+673 \mathrm{~K} \mathrm{H}_{2}$ " treated. (c) Sample RMH093, " $\mathrm{N}_{2} \mathrm{H}_{4}$-only" treated. (d) Sample RMH093, " $\mathrm{N}_{2} \mathrm{H}_{4}+673 \mathrm{~K} \mathrm{H}_{2}$ " treated. (e) Sample RMH014, " $\mathrm{N}_{2} \mathrm{H}_{4}$-only" treated.

sion. The chemisorption results give a strong indication that in catalyst RMH093 some Au must be present in a state of high dispersion below the detection limit of
WAXS. At this point let us recall the EDS results indicating that some of the small $(<4$ $\mathrm{nm}$ ) particles contained $\mathrm{Ru}$ with a trace of $\mathrm{Au}$. Thus, it seems reasonable to model 

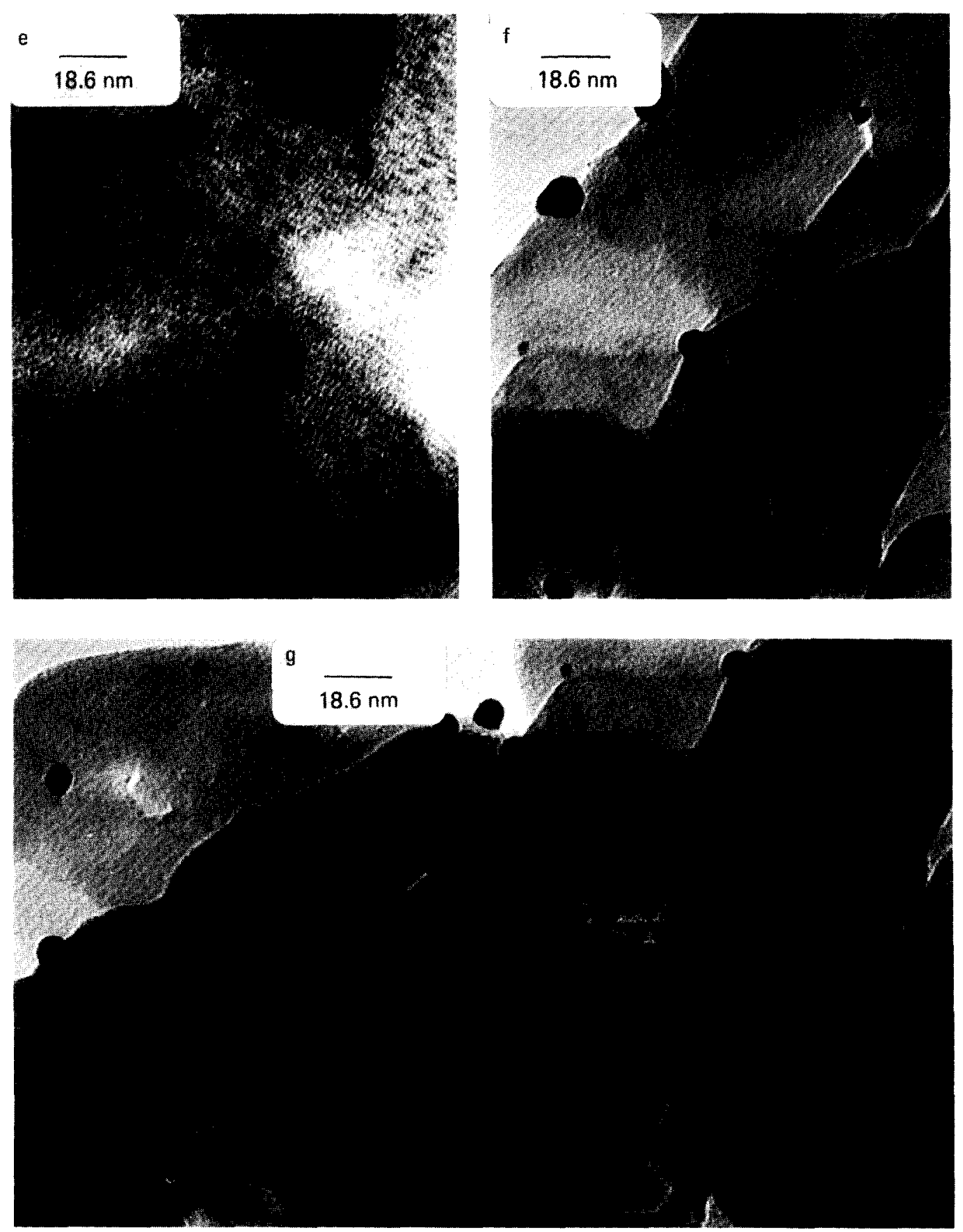

(f) Sample RMH014, " $\mathrm{N}_{2} \mathrm{H}_{4}+673 \mathrm{~K} \mathrm{H}_{2}$ " treated. (g) Other specimen area of sample RMH014, " $\mathrm{N}_{2} \mathrm{H}_{4}$ $+673 \mathrm{~K} \mathrm{H}_{2}$ " treated. Certain metal particles appear to be sandwiched between thin plates of $\mathrm{MgO}$.

these small particles as either monometallic $\mathrm{Ru}$ particles or $\mathrm{Ru}$ particles having some Au adsorbed on their surface.

On the Au-rich catalyst RMH014, TEM showed after " $\mathrm{N}_{2} \mathrm{H}_{4}$-only" treatment faint scattering centers attributable to $\mathrm{Ru}$ together with large monometallic $\mathrm{Au}$ particles. In the " $\mathrm{N}_{2} \mathrm{H}_{4}+673 \mathrm{~K} \mathrm{H}_{2}$ "'-treated 

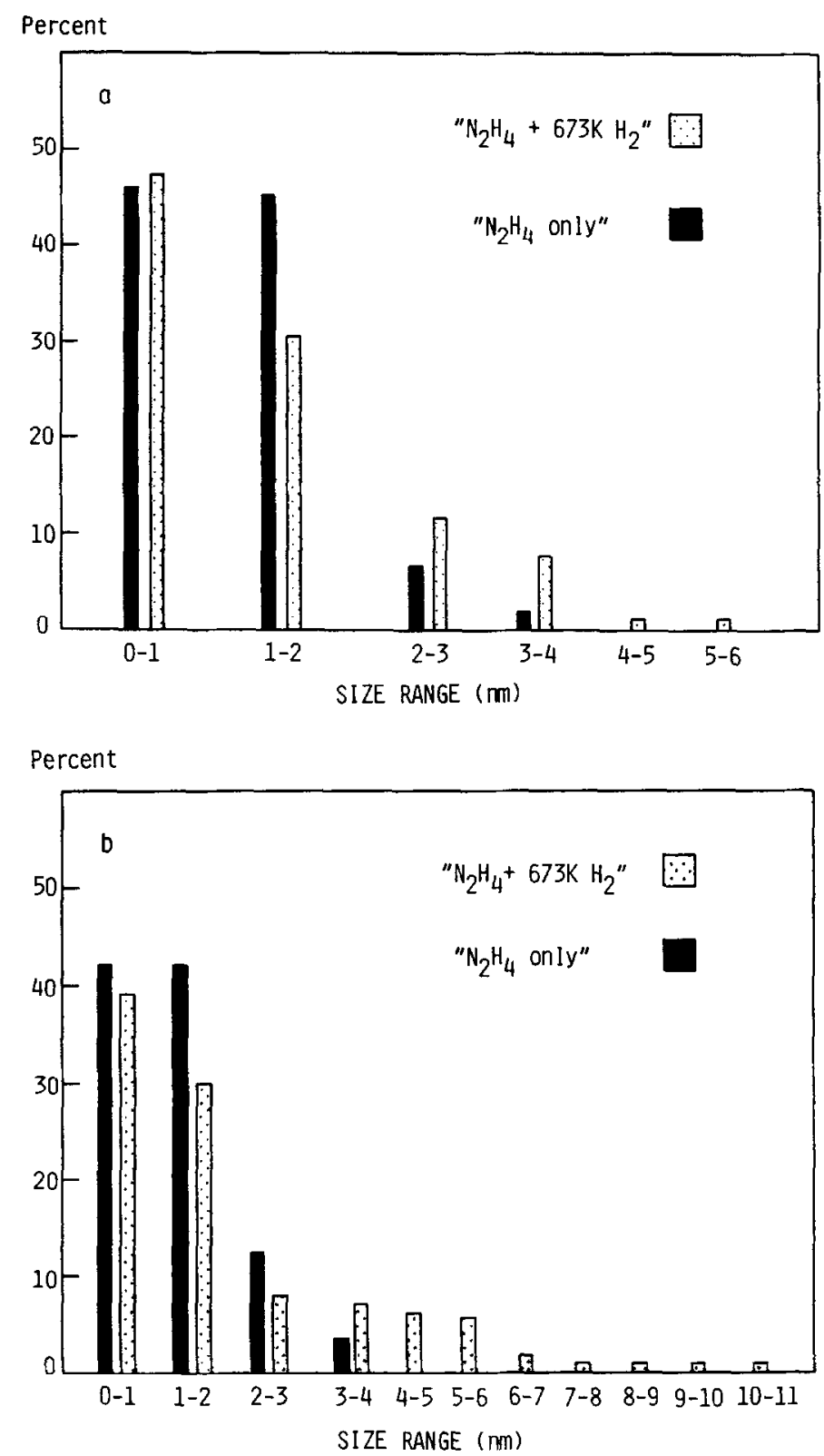

FIG. 3. Histograms showing the particle size distribution of both " $\mathrm{N}_{2} \mathrm{H}_{4}$-only" treated and " $\mathrm{N}_{2} \mathrm{H}_{4}+$

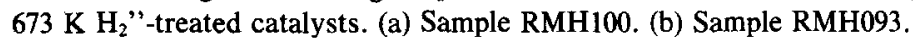

sample, the small $\mathrm{Ru}$ scattering centers were not seen (Figs. 2f,g). Interestingly, EDS analysis and WAXS failed to detect the presence of any large Ru particles even though the calculations based on chemisorption indicated an average $\mathrm{Ru}$ particle size of $20.3 \mathrm{~nm}$. Similarly, a much larger $\mathrm{Au}$ particle size is derived from the chemisorp- tion data than seen in WAXS or TEM. Therefore, the model previously proposed for catalyst RMH093, where gold adsorbs on the surface of $\mathrm{Ru}$ and consequently blocks part of the Ru surface from gas adsorption, is not applicable in the case of RMH014. Both Ru and Au seem to be partially inaccessible to gas chemisorption. If 

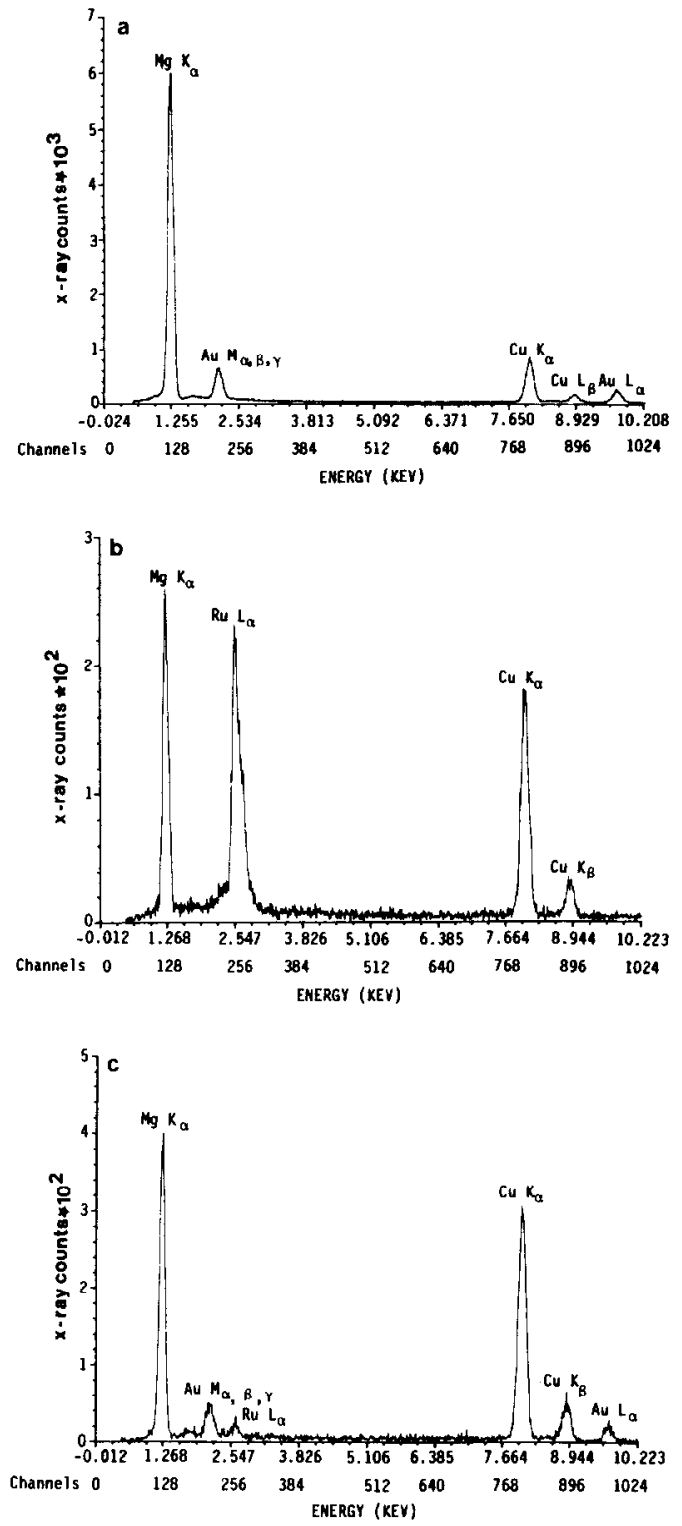

FIG. 4. Typical EDS spectra obtained for " $\mathrm{N}_{2} \mathrm{H}_{4}+$ $673 \mathrm{~K} \mathrm{H}_{2}$ "-treated catalyst samples. The $\mathrm{Cu}$ signals seen in the spectra are due to the use of Cu sample grids. (a) Sample RMH014, 20-nm particle containing Au only. (b) Sample RMH093, 4-nm particle containing Ru only. (c) Sample RMH014, 4-nm particle containing both $\mathrm{Ru}$ and Au. Different $\mathrm{Ru} / \mathrm{Au}$ signal ratios were found depending on the particle investigated.

one envisions a scenario where some $\mathrm{Ru}$ and $\mathrm{Au}$ particles are buried under $\mathrm{MgO}$ structures during the dehydration process accompanying the $\mathrm{H}_{2}$ reduction at $673 \mathrm{~K}$, then one can account for the inaccessibility of gases to a part of the metal sites. A careful examination of the micrographs (Figs. $2 f, g$ ) shows that indeed some support platelets are superimposed one on top of the other. It is conceivable that small metal particles get sandwiched between two $\mathrm{MgO}$ platelets in the course of the restructuring events of the support which occur during the dehydration of $\mathrm{Mg}(\mathrm{OH})_{2}$. Metal particles covered by thin $\mathrm{MgO}$ overlayers would be detectable in both WAXS and TEM experiments but unable to chemisorb gases.

Table 5 presents the average metal particle sizes of the " $\mathrm{N}_{2} \mathrm{H}_{4}+673 \mathrm{~K} \mathrm{H}_{2}$ "-treated catalysts (RMH $X X X$ series) as estimated from chemisorption and measured by WAXS. For comparison, previously reported data on $\mathrm{H}_{2}$-only-reduced $\mathrm{Ru}-\mathrm{Au} /$ $\mathrm{SiO}_{2}$ (RSXXX series) (8) and $\mathrm{Ru}-\mathrm{Au} / \mathrm{MgO}$ (RMXXX series) catalysts (9) are also included. Reduction of MgO-supported catalysts in $\mathrm{N}_{2} \mathrm{H}_{4}$ can lead to substantially higher $\mathrm{Ru}$ and $\mathrm{Au}$ dispersions compared to the conventional $\mathrm{H}_{2}$ reduction. It should be

\section{TABLE 5}

Comparison of Average Metal Particle Sizes Derived from Stepwise Chemisorption and WAXS for various $\mathrm{Ru}-\mathrm{Au}$ Catalysts

\begin{tabular}{|c|c|c|c|c|}
\hline \multirow[t]{3}{*}{ Sample code } & \multicolumn{4}{|c|}{ Average metal particle size (nm) } \\
\hline & \multicolumn{2}{|c|}{$\begin{array}{c}\text { Estimated } \\
\text { from } \\
\text { chemisorption }\end{array}$} & \multicolumn{2}{|c|}{$\begin{array}{c}\text { Determined } \\
\text { by } \\
\text { WAXS }\end{array}$} \\
\hline & $\mathbf{R u}$ & $\mathrm{Au}$ & Ru & $\mathrm{Au}$ \\
\hline RMH100 & 2.8 & - & $<4.0$ & - \\
\hline RMH093 & 5.1 & 6.7 & $<4.0$ & 23.4 \\
\hline RMH014 & 20.3 & 34.6 & $<4.0$ & 20.2 \\
\hline RS100 & 3.4 & 一 & $<4.0$ & - \\
\hline RS091 & 3.3 & 12.3 & $<4.0$ & 44.8 \\
\hline RS048 & 3.6 & 13.6 & $<4.0$ & 38.7 \\
\hline RS014 & 2.9 & 8.1 & $<4.0$ & 23.7 \\
\hline RM100 & 12.9 & - & 14.4 & - \\
\hline RM089 & 11.6 & 53.1 & 15.5 & 55.0 \\
\hline RM064 & 8.0 & 35.2 & $<4.0$ & 26.5 \\
\hline RM010 & 6.3 & 35.0 & $<4.0$ & 35.0 \\
\hline
\end{tabular}


noted that the Ru dispersion achieved in the monometallic $\mathrm{Ru} / \mathrm{MgO}$ catalyst $\mathrm{RMH} 100$ is comparable to that of the $\mathrm{Ru} / \mathrm{SiO}_{2}$ catalyst RS100. This result is quite remarkable for conventional wet impregnation of an $\mathrm{MgO}$ support with $\mathrm{RuCl}_{3}$ precursor salt solution followed by $\mathrm{H}_{2}$ reduction at $673 \mathrm{~K} . \mathrm{N}_{2} \mathrm{H}_{4}$ solutions in aqueous $\mathrm{Na}(\mathrm{OH})$ obviously exert a neutralizing influence on the acidic $\mathrm{RuCl}_{3}$ precursor solution leading to different metal deposition and nucleation characteristics. The metal dispersions after $\mathrm{N}_{2} \mathrm{H}_{4}$ reduction are very high. Subsequent $\mathrm{H}_{2}$ reduction at $673 \mathrm{~K}$ leads to considerable metal particle growth and agglomeration probably due to the high metal mobility during the phase transformation and restructuring of the support. Nevertheless, the final result is a much higher ruthenium dispersion than expected for $\mathrm{MgO}$-supported $\mathrm{Ru}-\mathrm{Au}$ catalysts prepared by wet impregnation and $\mathrm{H}_{2}$ rediction. Once the $\mathrm{N}_{2} \mathrm{H}_{4}$-reduced catalysts have heen treated in $\mathrm{H}_{2}$ at $673 \mathrm{~K}$, the particle size distribution appears to be rather stable even under prolonged exposure to typical catalytic reaction environments. The activity-suppressing "negative support effect" of $\mathrm{MgO}$ was found to be absent in the $\mathrm{N}_{2} \mathrm{H}_{4}$-reduced $\mathrm{Ru}$ / $\mathrm{MgO}$ catalyst RMH100, and the catalytic activity for $\mathrm{CO}$ hydrogenation was comparable to that of metallic $\mathrm{Ru}(25)$.

\section{CONCLUSIONS}

It is generally difficult to achieve high Ru metal dispersions by wet impregnation of $\mathrm{MgO}$ with chlorine-containing precursors such as $\mathrm{RuCl}_{3} \cdot \mathrm{H}_{2} \mathrm{O}$. The basic nature of $\mathrm{MgO}$ causes the precipitation of $\mathrm{Ru}$ in the form of large $\mathrm{Ru}(\mathrm{OH})_{3}$ particles. Prereduction of the catalysts in hydrazine prior to reduction in $\mathrm{H}_{2}$ at $673 \mathrm{~K}$ leads to much higher Ru metal dispersions. The differences in Ru metal dispersion appear to be linked to the morphology and the chlorine content of the support. Chlorine tends to prevent the formation of high-surface-area
$\mathrm{MgO}$. Hydrazine treatment leads to almost complete removal of residual chlorine contamination from the $\mathrm{MgO}$ support. In the absence of chlorine contamination, the BET surface area of $\mathrm{MgO}$ can increase significantly upon dehydration, and consequently high metal dispersions are facilitated. Numerous small metal particles are seen, some of them apparently in the form of small, two-dimensional rafts completely wetting the support. It should be noted that the chlorine-free, hydrazine-treated $\mathrm{Ru} /$ $\mathrm{MgO}$ catalyst RMH100 exhibits a CO hydrogenation activity similar to that of Ru metal or $\mathrm{Ru} / \mathrm{SiO}_{2}$, while conventionally prepared $\mathrm{Ru} / \mathrm{MgO}$ catalysts containing relatively high amounts of residual chlorine have severely suppressed catalytic activity. The suppression of the activity of MgOsupported Ru could be either a direct consequence of the presence of chlorine in the vicinity of Ru or an indirect effect of chlorine via a modification of the $\mathrm{MgO}$ morphology or the $\mathrm{Ru} / \mathrm{MgO}$ interface. $\mathrm{MgO}$ morphologies are known to be highly sensitive to the preparation route, impurity content, and thermal history. These factors strongly influence the adsorption characteristics of $\mathrm{MgO}$. It is quite likely that these variations in adsorption characteristics carry to some extent over into the deposition of metal precursor ions on the support. This could change the nucleation and growth of metal particles and result in different manifestations of metal-support interactions.

The formation of bimetallic $\mathrm{Ru}-\mathrm{Au}$ particles does not seem to be significantly influenced by hydrazine treatment. As in the previously investigated $\mathrm{H}_{2}$-reduced $\mathrm{Ru}$ $\mathrm{Au} / \mathrm{MgO}$ catalyst series, bimetallic $\mathrm{Ru}-\mathrm{Au}$ particles are restricted to particle sizes of less than $5 \mathrm{~nm}$. Evidence for encapsulation of some metal particles by platelets of $\mathrm{MgO}$ was discovered. The encapsulation does not seem to be a direct consequence of hydrazine reduction, but may be linked to the structural changes of the $\mathrm{Mg}(\mathrm{OH})_{2} / \mathrm{MgO}$ system during dehydration. 


\section{ACKNOWLEDGMENTS}

The authors thank Dr. S. Galvagno and Dr. G. R. Tauszik for their contribution to catalyst preparation and characterization, and Dr. A. K. Datye and Dr. J. Y. Lee for their helpful suggestions. Skillful experimental assistance in part of the work was provided by Mr. M. Ballard. Financial support by the National Science Foundation and the Army Research Office is gratefully acknowledged.

\section{REFERENCES}

1. Dayte, A. K., and Schwank, J., "Proceedings of the 8th International Congress on Catalysis, Berlin 1984," Vol. IV, p. 587. Verlag Chemie, Weinheim, 1984.

2. Datye, A. K., and Schwank, J., J. Catal. 93, 256 (1985).

3. Datye, A. K., Lee, J. Y., Shastri, A. G., and Schwank, J., "AICHE Annual Meeting, 1984, San Francisco," Paper No. 53a.

4. Tauszik, G. R., Leofanti, G., and Galvagno, S., J. Mol. Catal. 25, 357 (1984).

5. Tauszik, G. R., Garbassi, F., and Marzi, A., Gazz. Chim. Ital. 110, 443 (1980).

6. Bassi, I. W., Garbassi, F., Vlaic, G., Marzi, A., Tauszik, G. R., Cocco, G., Galvagno, S., and Parravano, G., J. Catal. 64, 405 (1980).

7. Galvagno, S., Schwank, J., Parravano, G., Garbassi, F., Marzi, A., and Tauszik, G. R., J. Catal. 69, 283 (1981)

8. Shastri, A. G., and Schwank, J., J. Catal. 95, 271 (1985).

9. Shastri, A. G., and Schwank, J., J. Catal. 95, 284 (1985).

10. Freund, F., and Sperling, V., Mater. Res. Bull. 11, 621 (1976).

11. Goodman, J. F., Proc. R. Soc. London Ser. A 247, 346 (1958).

12. Phillips, V. A., Opperhauser, H., and Kolbe, J. L., J. Amer. Ceram. Soc. 61, 75 (1978).
13. Freund, F., Martens, A., and Scheikh-Ol-Eslami, N., J. Therm. Anal. 8, 525 (1975).

14. Rhodes, W. H., and Wuensch, B. J., J. Amer. Ceram. Soc. 56, 495 (1973).

15. Terauchi, H., Ohga, T., and Naono, H., Solid State Commun. 35, 895 (1980).

16. Garn, P. D., Kawalek, B., and Chang, J.-C., Thermochim. Acta 26, 375 (1978).

17. Gordon, R. S., and Kingery, W. D., J. Amer. Ceram. Soc. 49, 654 (1966).

18. Guilliatt, I. F., and Brett, N. H., Philos. Mag. Ser. B 23, 647 (1971).

19. Anderson, P. J., and Horlock, R. F., Trans. Faraday Soc. 58, 1993 (1962).

20. Leofanti, G., Solari, M., Tauszik, G. R., Garbassi, F., Galvagno, S., and Schwank, J., Appl. Catal. 3, 131 (1982).

21. Shastri, A. G., Chae, H. B., Bretz, M., and Schwank, J., J. Phys. Chem. 89, 3761 (1985).

22. Schwank, J., Galvagno, S., and Parravano, G., $J$. Catal. 63, 415 (1980).

23. Schwank, J., Shastri, A. G., and J. Y. Lee, “189th ACS National Meeting, Miami Beach,"' 1985.

24. Goldwasser, J., Bolivar, C., Ramon Ruiz, C., Arenas, B., Wanke. S., Royo, H., Barrios, R., and Giron, J., "Proceedings of the 8 th International Congress on Catalysis, Berlin 1984," Vol. V, p. 195. Verlag Chemie, Weinheim, 1984.

25. Datye, A. K., Ph.D. thesis, University of Michigan, 1984.

26. Outka, D. A., and Madix, R. J., "189th ACS National Meeting, Miami Beach," 1985.

27. Sault, A., Madix, R. J., and Campbell, C. T.. in preparation.

28. Canning, N., Outka, D. A., and Madix, R. J., Surf. Sri. 141, 240 (1984).

29. Goodman, W. D., and Peden, C. H., "Ninth North American Meeting of the Catalysis Society, Houston," 1985.

30. Gerberich, H. R., Cant, N. W., and Hall, W. K., J. Catal. 16, 204 (1970). 